\title{
OPERATOR WHOLE-BODY VIBRATION EXPOSURE OF WHEELED FORWARDER WITH BOGIE TRACKS
}

Ricardas Butkus, Gediminas Vasiliauskas, Remigijus Zinkevicius

Vytautas Magnus University, Lithuania

ricardas.butkus@vdu.lt, gediminas.vasiliauskas@vdu.lt, remigijus.zinkevicius@vdu.lt

\begin{abstract}
Exposure to whole-body vibration (WBV) is one of the common occupational risk factors for the operators of self-propelled machinery including forwarders. It leads to the problems of lower back pain while long-term exposure causes occupational musculoskeletal diseases. Level of the total vibration exposure is the product of multiple factors, which include forwarder properties, terrain, forwarding distances, driving style and others. The aim of this study was to evaluate and compare the difference in operator whole body vibration in the full cycle of wood extraction using a wheeled forwarder and wheeled forwarder with tracks. The results were collected measuring the vibration acceleration on the seat of a brand-new forwarder. The results show that the vibration levels were slightly lower when the forwarder was operated with tracks. The calculated average $A(8)$ exposure of the wheeled forwarder was $0.46 \mathrm{~m} \cdot \mathrm{s}^{-2}$ compared with $0.33 \mathrm{~m} \cdot \mathrm{s}^{-2}$ when the wheeled forwarder was operated with tracks. The results, however, show that the highest whole-body vibration is, when the logs are being transported to the unload location and when the empty forwarder travels back to the site unloaded. These results reveal that long transportation distances are not desirable not only from the productivity point of view, but also might have bigger harm on the operators' health.
\end{abstract}

Keywords: operator, forwarder, whole body vibration.

\section{Introduction}

Whole body vibration (WBV) effects on the operators of various self-propelled machinery has been investigated widely over the last decades. It has been proven that long-term exposure to whole body vibration is the cause of multiple musculoskeletal symptoms, such as pain in lower back and shoulders [1]. The evidence and the correlation of these symptoms to WBV was performed by Burstrom [2] in the extensive review of the published evidence. It was found that workers who are exposed to WBV have an increased risk of lower back pain. These results are like those obtained by Choina [3], where pain complaints of forestry workers were analysed. The results revealed that the largest percentage of forestry workers complain about lower part spine pain, which is mainly caused by WBV. It was concluded that driving a vehicle over long distances along an uneven terrain might be a risk factor for the low back pain [3], but not for the neck pain [4].

Vibration exposure of forwarder and harvester operators was investigated also in multiple studies [5-8]. In order to make the vibration level comparisons of the various machines, standardized vibration test-tracks are used. They have the standardized profile, which consists of multiple variously shaped bumps for left and right wheels [9]. However, these conditions are good for comparison, but might sometimes be misleading as do not reflect the real-life conditions. For this reason, there are more studies available, which use the evaluation of vibration exposure in full cycle of wood extraction in real life conditions, which typically includes four forwarding operations (Fig. 1). The calculation of the vibration exposure in this case consists of the measurement of vibration acceleration of each operation and the duration of each operation per working day $(8 \mathrm{hrs}$.)

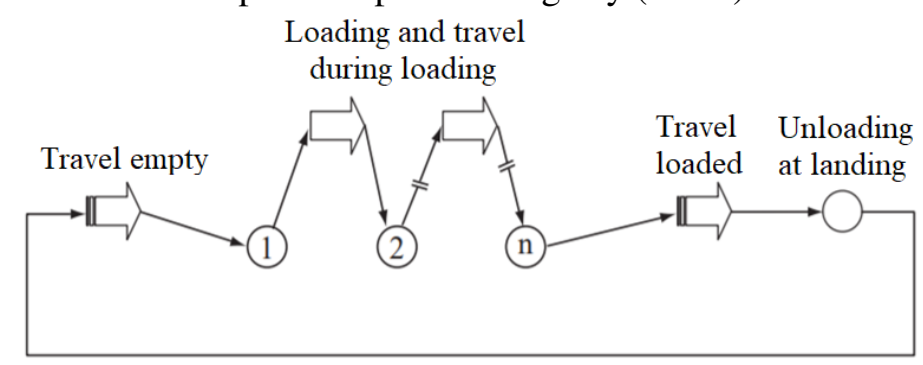

Fig. 1. Typical operations for the evaluation of whole-body vibration of the forwarder [10]

Results provided in these studies are similar, as indicate the highest vibration acceleration values for forwarder transport operations. In the study of Rehn [5], it was found that the average vibration total value (VTV) of empty transport operations was $1.69 \pm 0.6 \mathrm{~m} \cdot \mathrm{s}^{-2}$ and $1.1 \pm 0.53 \mathrm{~m} \cdot \mathrm{s}^{-2}$ of loaded transport. It was also found that vibration values were significantly lower for loading and unloading 
$\left(0.55 \mathrm{~m} \cdot \mathrm{s}^{-2}\right.$ and $0.41 \mathrm{~m} \cdot \mathrm{s}^{-2}$ respectively). These results show that WBV tends to change over time during the work-shift. This means that worker exposure should be evaluated also considering the time factor, which is included to the calculation of daily exposure $A(8)$.

The time factor of forestry operations is also a significant component, but, in most studies, it is evaluated from the perspective of productivity rather than occupational exposure. Significant differences were reported between the productivity of harvester operators which might be as high as two times [11]. This can be closely related with the duration of the operations and to the vibration exposure at the same time. It was reported in multiple studies [4-5] that typical time structure of the forwarding cycle is to 7-15\% for empty travel, $32-59 \%$ for loading, 3-20\% for full travel $6-22 \%$ for unloading travel empty. As the travelling time duration can strongly depend on the forwarding distance, it can consist up to more than $30 \%$ for long travelling distances. For this reason, changing the driving speed might increase the hauling productivity, but reduce the driving comfort of the operator, i.e. increase the operator vibration exposure.

The comparison of the operator whole body vibration of the tracked forwarder has been evaluated in a very limited number of studies [12], while most of the studies analyse soil compaction and fuel consumption issues. For this reason, the purpose of this study was to investigate the influence of tracked bogie axle of the forwarder on driver comfort and whole- body vibration exposure.

\section{Materials and methods}

Field study was carried out in the forest compartment located in central Lithuania, Kèdainiai distr., Lančiūnava. Measurements were carried out with the experimental machine, which was a new ten-wheel driven HSM 208F forwarder prototype (Fig. 2). The net weight of the machine without tracks was 24 tons (tracked 31 tons) and the tire pressure of 3.5 psi for front and 3.8 for rear axle tires.Driver seat was adjusted to the weight of the operator, which was $820 \mathrm{~N}$.

The forest in the location was harvested by chainsaws and the wood extracted over the skidtrails from the stump to a landing outside the forest, where they were later loaded onto trucks.Distance from the stump location to the log storage location was $\sim 1$ kilometer (transportation distance) over arable land. The surface on the stall site was a turfy soil with several stumps on the skid-trail (Fig. 3). Comfortable driving speed for full and empty travel on site was $\sim 2.5 \mathrm{~km} \cdot \mathrm{h}^{-1}$ and $10 \mathrm{~km} \cdot \mathrm{h}^{-1}$ for transport outside the forest.In order to evaluate the speed influence on human vibration, the machine was tested at multiple speeds $\left(5,10,15 \mathrm{~km} \cdot \mathrm{h}^{-1}\right)$ in the transportationdistance of 1 kilometer.

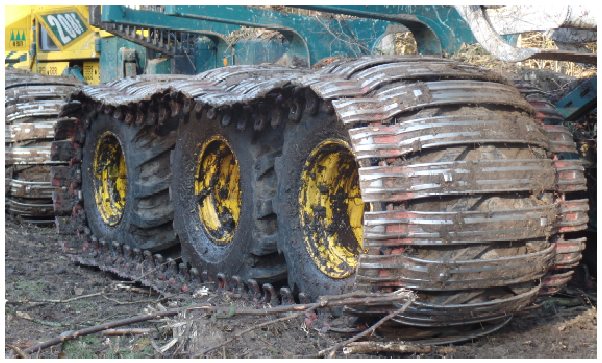

Fig. 2. View of therear tracked forwarder axle

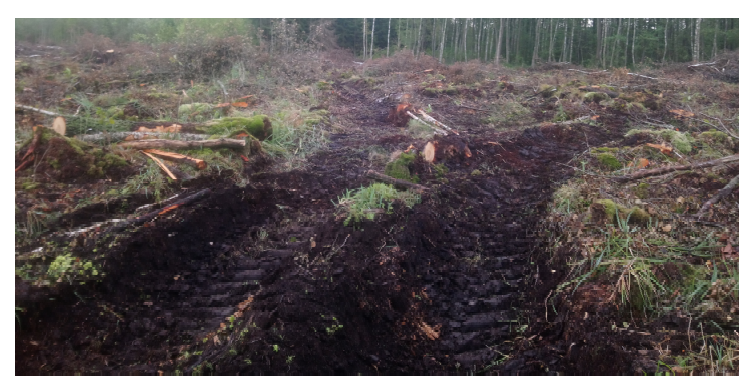

Fig. 3. View of the test site and the skid trail after multiple forwarder passes

Field tests were carried out during typical forwarding, when the forwarder was moving on the skid trail with and without tracks on front and rear axles. Average moving distance on the site to get fully loaded was $350 \mathrm{~m}$ on average.The load was on average 15 cubic meters pine, black alder and birch. Measurements were carried out at the same location and the forwarder was operated by the same operator, which eliminates the influence of multiple driver variation. Vibration was measured during a typical working day, so it is representative from a practical point of view, but the conditions (no. of movements with the crane, driving distance, weight of logs) might be slightly different. These circumstances were not considered in our study.

\section{Vibration measurement and evaluation}

Whole body vibration measurements were carried out according to the requirements provided in ISO 2631-1 [13]. Data were collected using the human vibration analyser Bruel\&Kjaer type 4447 with 
the type 4515-B-002 seat pad including a type 4524-B accelerometer. Measurement accelerometer integrated into a seat pad was put on the seat of the operator and connected to the hand-held vibration analyser (Fig. 3). Measurement results, which were the RMS x, y, z values, logged (1s) data and other vibration parameters were later transferred to computer for analysis. Duration of the vibration measurements was started and stopped manually at the beginning and the end of each operation.

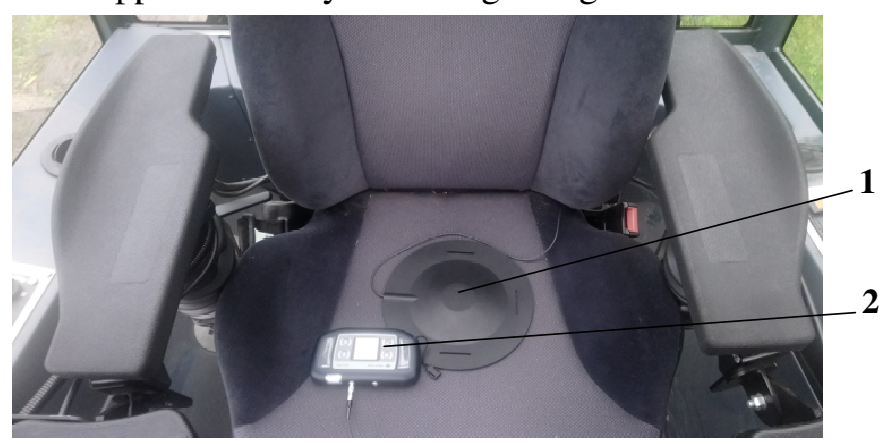

Fig. 3. Whole body vibration measurement instrumentation: 1 - seat pad accelerometer;

2 - human vibration analyser Bruel\&Kjaer type 4447

WBV evaluation was done assessing the frequency weighted RMS values $\left(a_{w}\right)$ in three orthogonal directions $(x, y, z)$. The RMS magnitudes were expressedaccording to the equation 1 as provided in ISO 2631-1 [13]:

$$
a_{w}=\sqrt{\left[\frac{1}{T} \int_{0}^{T} a_{w}^{2}(t) d t\right]}, \mathrm{m} \cdot \mathrm{s}^{-2}
$$

where $a_{w}(t)$ - weighted acceleration as a function of time, $\mathrm{m} \cdot \mathrm{s}^{-2}$;

$T$-duration of the measurement, s.

Sum of the vibration magnitudes $a_{w, x}, a_{w, y}$ and $a_{w, z}$ give the vibration total value VTV $\left(a_{v}\right)$ which is calculated by applying the correction factors $k_{x, y, z}$ for all vibration directions. Vibration total value was then calculated as follows:

$$
a_{v}=\sqrt{k_{x}^{2} a_{w x}^{2}+k_{y}^{2} a_{w y}^{2}+k_{z}^{2} a_{w z}^{2}}, \mathrm{~m} \cdot \mathrm{s}^{-2}
$$

where $k_{x}, k_{y}, k_{z}$ - sensitivity factors $(1.4 ; 1.4$ and 1 respectively);

$a_{w, x}, a_{w, y}, a_{w, z}-$ measured vibration acceleration in $\mathrm{x}, \mathrm{y}, \mathrm{z}$ axis, $\mathrm{m} \cdot \mathrm{s}^{-2}$.

Vibration exposure was evaluated as provided in the EU Directive 2002/44/EC [14]. Exposure action value for whole body vibration is fixed at $A(8) \leq 0.5 \mathrm{~ms}^{-2}$ while exposure limit value $A(8) \leq 1.15$ $\mathrm{ms}^{-2}$. Exposure values are fixed at $0.5 \mathrm{~ms}^{-2}$ and $1.15 \mathrm{~ms}^{-2}$ respectively.

Vibration exposure value $\mathrm{A}(8)$ was calculated as follows:

$$
A(8)=\sqrt{\frac{1}{T_{0}}} \sum_{i=1}^{n} a_{w i}^{2} T_{i}
$$

where $a_{w i}$-frequency weighted acceleration average during operation $i$;

$T_{i}$ - duration of operation $i$ in seconds;

$T_{0}$ - reference $8 \mathrm{~h}$ work-shift duration in seconds.

Vibration measurements were carried out for all operations of the wood forwarding cycle, as given in Fig. 1 for the wheeled and wheeled-tracked forwarder. The collected values then were averaged and the vibration exposurewas calculated. WBV results are presented as mean values with the confidence level of $95 \%$ probability.

\section{Results and discussion}

An overview of the obtained measurement results for the wheeled and wheeled-tracked forwarder is provided in Table 1. The time study analysis shows that the average time spent for empty travel, 
loading ant travel during loading, full travel and unloading were $11 \%, 62 \%, 12 \%, 15 \%$ for the wheeled forwarder and $12 \%, 5 \%, 15 \%, 14 \%$ for the tracked forwarder respectively.

From the data in Table 2 it can be seen that, in general, mean vibration acceleration $a_{v}$ was the highest for travel operations, while the log loading and unloading values were much lower when the forwarder was operated without tracks. When the tracks were used, these values significantly reduced, probably, because of the significantly increased total mass of the machine. These results also show almost no difference in loading and unloading operations when the forwarder was used with and without tracks.

Table 1

Mean durations and vibration accelerations in operations of wood extraction cycle

\begin{tabular}{|c|c|c|c|c|c|c|}
\hline \multirow{2}{*}{ Loading } & \multicolumn{3}{|c|}{ Wheeled forwarder } & \multicolumn{3}{c|}{ Tracked forwarder } \\
\cline { 2 - 7 } & $\begin{array}{c}\text { Average } \\
\text { duration, s }\end{array}$ & $\begin{array}{c}\text { Time } \\
\text { percentage, } \%\end{array}$ & $a_{v}, \mathrm{~m} \cdot \mathrm{s}^{-2}$ & $\begin{array}{c}\text { Average } \\
\text { duration, s }\end{array}$ & $\begin{array}{c}\text { Time } \\
\text { percentage, } \%\end{array}$ & $a_{v}, \mathrm{~m} \cdot \mathrm{s}^{-2}$ \\
\hline Travel empty & 420 & 11 & 0.84 & 466 & 12 & 0.18 \\
\hline $\begin{array}{c}\text { Loading and travel } \\
\text { during loading }\end{array}$ & 2475 & 62 & 0.34 & 2224 & 58 & 0.23 \\
\hline Travel loaded & 486 & 12 & 0.75 & 589 & 15 & 0.34 \\
\hline Unloading landing & 604 & 15 & 0.22 & 540 & 14 & 0.28 \\
\hline
\end{tabular}

The time percentage for each operation is important, as it strongly influences the $8 \mathrm{~h}$ exposure. For both tested cases (wheeled and tracked) in our study, the time spent for various tasks was within the limits provided in other studies, except that the loading operation was at its maximum value compared to the results of other researchers [5]. This was because of the small piles of the logs on the site, as well as there were a vast number of individual logs, loading of which is time consuming.

The calculated vibration exposure values from the measured results are given in Fig.4. The calculation of the $A(8)$ was done according to the time study data provided in Table 1 , for the $8 \mathrm{~h}$ working shift. The $T_{i}$ durations (see Equation 3 ) were calculated multiplying by the number of full cycles over the $8 \mathrm{~h}$ shift. For the case of the wheeled forwarder, there were 7.2 full cycles per working day, while for the tracked forwarder -7.5 respectively.

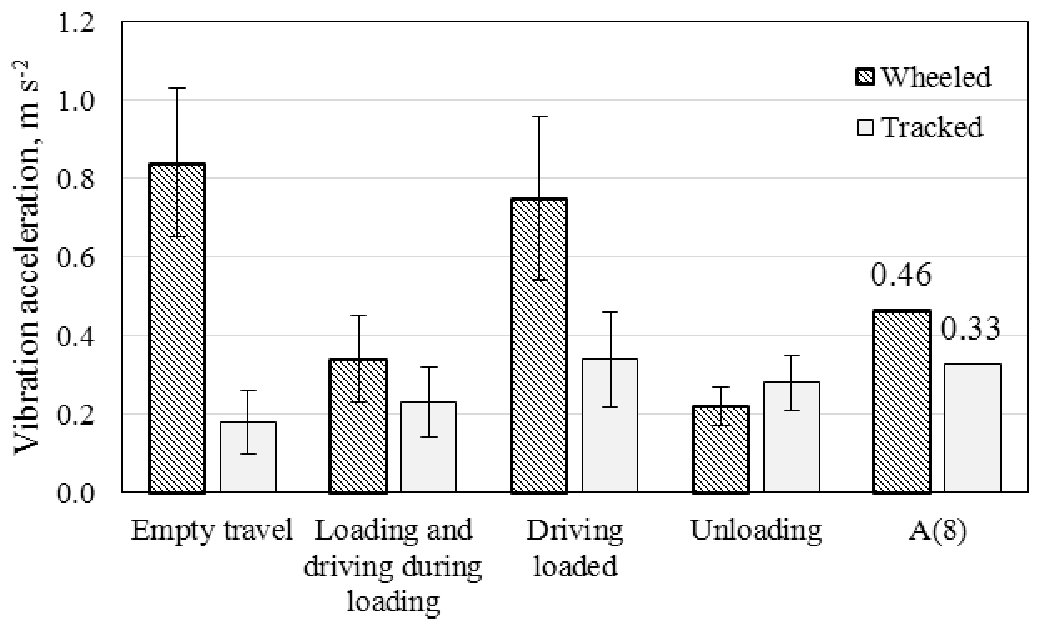

Fig. 4. Overview of the measured accelerations $a_{v}$ of various operations of the wheeled and tracked forwarder and calculated vibration exposure $A(8)$

These results agree with the results of other studies [5], where the same tendency of the highest vibration acceleration was also identified for transport operations. Also, it was found that vibration acceleration for empty travel might be reduced by the factor of four, while for the driving loaded $\sim 2$ times on average. As the driving distance in our study was not the highest and consisted 11-15\%, the influence of the tracked chassis would give even better results at long hauling distances (20-30\% of driving time), while the wheeled chassis would give higher exposure values. In order to compensate the effect of the increased driving time, the driving speed could be increased in order to reach the 
unload location faster. These results for the empty travelling are provided in Fig. 5. However, the results show that the vibration acceleration increases as the driving speed increases for both wheeled and tracked conditions.

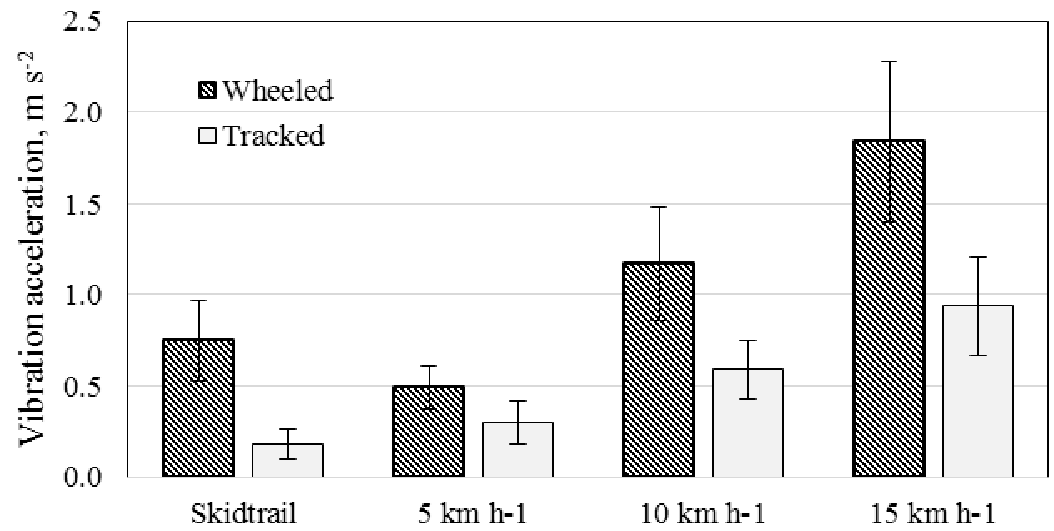

Fig. 5. Overview of the measured accelerations of empty travel when driving on a skid trail at various driving speeds from the site to unloading location

From these data we considered that the speed increase could give a positive effect on vibration exposure, as the driving duration decreases. Further, the calculations show that the time reduction is not as significant as the increase in vibration acceleration and the value of $A(8)$ parameter remains almost the same when the speed is increased. However, there is a significant effect on the operator comfort of the wheeled machine at especially high speeds $\left(10 \mathrm{~km} \cdot \mathrm{h}^{-1}\right.$ and $\left.15 \mathrm{~km} \cdot \mathrm{h}^{-1}\right)$. The vibration acceleration might reduce from 1.17 to $0.6 \mathrm{~m} \cdot \mathrm{s}^{-2}$ for the speed of $10 \mathrm{~km} \cdot \mathrm{h}^{-1}$ and from 1.84 to $0.94 \mathrm{~m} \cdot \mathrm{s}^{-2}$ for the speed of $15 \mathrm{~km} \cdot \mathrm{h}^{-1}$ respectively.

It is clear from the results that the tracked forwarder is much more advantageous from the perspective of human vibration. This effect can be explained by the principles of vibration damping. The ratio of the exciting frequency $\left(f_{e r r}\right)$ and the eigen frequency of the vibro-isolated system $\left(f_{0}\right)$ gives better damping characteristics. It is desirable to have this ratio $(\eta)$ as high as possible.

Eigen frequency of the vibro-isolated machine can be calculated according to the following equation [15]:

$$
f_{0}=\frac{1}{2 \pi} \sqrt{g \frac{C}{m}}
$$

where $g$-standard gravity, $\mathrm{m} \cdot \mathrm{s}^{-2}$

$C$ - physical-mechanical properties of the machine vibration isolation system, $\mathrm{kg} \cdot \mathrm{m}^{-1}$;

$m$ - mass, $\mathrm{kg}$.

This equation justifies the fact that the machine has similar physical-mechanical properties of the vibration isolation ( $c$ changes insignificantly except the damping of tires), but the additional mass of the tracks $\left(7000 \mathrm{~kg}\right.$ ) significantly reduces the value of $f_{0}$ and the exiting/eigenfrequency ratio.

These results obtained in our study in real forwarding conditions agree with the results in another study [9], where the speed influence was investigated on the test track. The authors found that doubling the speed might increase the vibration value by $50 \%$. It was also reported that the tracked forwarder can go faster by $50 \%$ to reach the same vibration acceleration value. In real life conditions we found even bigger effect of tracks on whole body vibration and the driver comfort.

\section{Conclusions}

1. The calculated whole-body vibration exposure was lower when the forwarder was operated without tracks. The calculated $A(8)$ value was $0.46 \mathrm{~m} \cdot \mathrm{s}^{-2}$ for the wheeled forwarder and $0.33 \mathrm{~m} \cdot \mathrm{s}^{-2}$ for the tracked forwarder when the working cycle consists of four operations, duration which 1162-12-15 percent respectively.

2. The speed influence on the vibration acceleration and operator WBV exposure has a crucial effect, especially when the forwarder is operated without tracks. The driving speed increase from 
5 to 10 and $15 \mathrm{~km} \cdot \mathrm{h}^{-1}$ also increases the vibration acceleration from $0.49 \mathrm{~m} \cdot \mathrm{s}^{-2}$ to $1.17 \mathrm{~m} \cdot \mathrm{s}^{-2}$ and $1.84 \mathrm{~m} \cdot \mathrm{s}^{-2}$ respectively.

3. When forwarding with a tracked machine, the vibration acceleration values reduced significantly for unloaded (up to 4 times) and loaded (up to 2 times) driving operations compared to the wheeled forwarding. As these operations have the crucial effect on total exposure, it can be concluded that the use of tracks can be an option for improvement of the forwarder driver comfort.

\section{Acknowledgements}

This research has received funding from the European Union Horizon 2020 research and innovation programme under grant agreement No 727883 .

\section{References}

[1] Rehn B., Bergdahl I.A., Ahlgren, C. Musculoskeletal symptoms among drivers of all-terrain vehicles. Journal of Sound and Vibration, vol. 253(1), 200, pp. 21-29.

[2] Burström L., Nilsson T., Wahlström J. Whole-body vibration and the risk of low back pain and sciatica: a systematic review and meta-analysis International Archives of Occupational and Environmental Health, Volume 88, 2015, No. 4, pp. 403-418.

[3] Choina, P., Solecki, L., Goździewska, etc. Assessment of musculoskeletal system pain complaints reported by forestry workers. Annals of Agricultural and Environmental Medicine, 2018, 25(2), pp. 338344.

[4] Rehn B., Nilsson T., Lundström R., etc. Neck pain combined with arm pain among professional drivers of forest machines and the association with whole-body vibration exposure. Ergonomics, vol. 52(10), 2009, pp. 1240-1247.

[5] Rehn B., Lundström R., Nilsson L., etc. Variation in exposure to whole-body vibration for operators of forwarder vehicles - aspects on measurement strategies and prevention. International Journal of Industrial Ergonomics, vol. 35(9), 2005, pp. 831-842.

[6] Poje A., Grigolato S., Potočnik I. Operator Exposure to Noise and Whole-Body Vibration in a Fully Mechanised CTL Forest Harvesting System in Karst Terrain. Croatian Journal of Forest Engineering, vol. 40, 2019, pp. 139-250.

[7] Häggström C., Öhman M., Burström L., etc. Vibration exposure in forwarder work: Effects of work element and grapple type. Croatian Journal of Forest Engineering, vol. 37(1), 2016, pp. 107118.

[8] Marsili A., Ragni L., Vassalini G. Vibration and Noise of a Tracked Forestry Vehicle, Journal of Agricultural Engineering Research, Vol. 70, Iss. 3, 1998, pp. 295-306.

[9] Cheng C.Modeling of the Ride Comfort of a Forwarder [online] [15.02.2020]. Available at: http://www.diva-portal.org/smash/get/diva2:440746/fulltext01

[10] Tiernan D., ZelekeG., Owende P.M.O etc. Effect of Working Conditions on Forwarder Productivity in Cut-to-length Timber Harvesting on Sensitive Forest Sites in Ireland. Biosystems Engineering, vol. 87, 2004, pp. 167-177. 10.1016/j.biosystemseng.2003.11.009.

[11] Purfürst T., ErlerJ.The precision of productivity models for the harvester-do we forget the human factor? Precision Forestry in Plantations, Semi-Natural and Natural Forests. Proceedings of the "International Precision Forestry Symposium", March 5-10, 2006, Stellenbosch University, South Africa, pp. 465-475.

[12] Bygdén G., Burström L., Wästerlund I. Any good vibrations with bogie tracks? Forest Res Eng Int J, Iss. 2(1), 2018, pp. 15-17.

[13] ISO 2631-1 (1997). Evaluation of Human Exposure to Whole-body Vibration - Part 1: General Requirements.

[14] European Union (2002). Directive 2002/44/EC of the European Parliament and of the Council of 25 June 2002 on the minimum health and safety requirements regarding the exposure of workers to the risks arising from physical agents (vibration) (sixteenth individual Directive within the meaning of Article 16(1) of Directive 89/391/EEC. Official Journal of the European Communities L 177.

[15] Melzig-Thiel Kinne J. Schwingungsschutz am Arbeitsplatz. Technischer Schwingungsschutz . Technik 12, 1998, Bundesanstlt für Arbeitschutz und Arbeitsmedicin, Dortmund.- S. 40. 